\title{
A modular design strategy considering sustainability and supplier selection
}

\author{
Masato INOUE*, Shuho YAMADA*, Shogo MIYAJIMA*, Katsuhide ISHII*, \\ Rina HASEBE*, Kazuhiro AOYAMA**, Tetsuo YAMADA*** and Stefan BRACKE**** \\ *Department of Mechanical Engineering Informatics, Meiji University \\ 1-1-1 Higashi-Mita, Tama-ku, Kawasaki, Kanagawa 214-8571, Japan \\ E-mail: m_inoue@meiji.ac.jp \\ ${ }^{*}$ RACE: Research into Artifacts, Center for Engineering, School of Engineering, The University of Tokyo \\ 7-3-1 Hongo, Bunkyo-ku, Tokyo 113-8656, Japan \\ ***Department of Informatics, The University of Electro-Communications (UEC Tokyo) \\ 1-5-1 Chofugaoka, Chofu-shi, Tokyo 182-8585, Japan \\ ${ }^{* * * *}$ Chair of Reliability Engineering and Risk Analytics, University of Wuppertal \\ Gaußstraße 20, Wuppertal 42119, Germany
}

Received: 4 July 2019; Revised: 3 January 2020; Accepted: 30 January 2020

\begin{abstract}
To utilize the residual value, which remains an idle asset and disposed product based on the circular economy package, the definition or clarification of such a value and the development of a scheme for such a reutilization is essential. In addition, to facilitate an efficient utilization of the residual value, a product or its components needs to be designed considering its future reuse, remanufacturing, and upgrading. When companies monitor product usage using the Internet of things, they can make proposals to users of appropriate lifecycle options such as reuse, remanufacturing, and upgrading and such proposals are conductive to customer retention for these companies. Therefore, an ideal situation is one in which the product is appropriately modularly designed and its components will be reused in an upward product or another product family or be recycled at the end of life. A designer needs to consider resource efficiency not only in the reuse stage but also in the production and procurement stages. In addition, a company that designs and manufactures products needs to strive for the simultaneous attainment of cooperate social responsibility, higher profits, and higher user satisfaction. Therefore, proper supplier selection is necessary because products currently consist of many components and modules manufactured by various companies. This study proposes a modular design and a strategic evaluation method based on the viewpoint of supply chain management considering sustainability and supplier selection simultaneously. In particular, the proposed method evaluates the designed modular strategy from the perspectives of cost, environmental load in production and transportation, quality, and procurement lead time. As an evaluation, the proposed indicator evaluates the efficiencies of the candidate suppliers. This study applied the proposed method to the design problem of a laptop module and determined the more appropriate suppliers with respect to each destination.
\end{abstract}

Keywords: Modular design, Supply chain management, Early design phase, Decision-making support, Product architecture, Upgrade design

\section{Introduction}

The attainment of sustainable consumption and production has been discussed as a global agenda. In Europe, for example, the European Commission adopted the circular economy (CE) package in 2015, which aims to obtain environmental and economic benefits by reusing or recycling the residual value that remains due to idle assets and disposed products (European Commission, 2020). In Japan, the concept of global multi-value circulation has also been discussed and proposed (Sustainability Design Institute, 2020). This concept integrates the production capacity of Asian 
countries with the system boundary of the $\mathrm{CE}$ and aims to promote the creation of sustainable societies not only in developed countries but also in developing countries.

To utilize the residual value that remains in an idle asset or a disposed product, defining and clarifying this value and developing a scheme to ensure reutilization are essential. In addition, the products and their components need to be designed taking into consideration future reuse or remanufacturing to facilitate the efficient use of the residual value. A schematic depiction of the ideal situation is presented in Fig. 1, in which a product exhibits an appropriate modular design and its components are reused in new products and other product families or are recycled at the end of the lifecycle of the original product. To adequately assess and optimize these processes, designers also need to consider the resource efficiency not only during the reuse stage but also during the production and procurement stages. In addition, product designers and manufacturers need to strive to simultaneously integrate social responsibility, achieve higher profits, and provide higher user satisfaction.

This study proposes a modular design strategy and its evaluation method from the perspective of supply chain management (SCM). More specifically, the proposed method evaluates the strategy from the perspectives of economic cost, environmental load, procurement lead time, and component quality. The proposed method also designs and evaluates the product architecture from the perspective of sustainability, in contrast to traditional modular design methods that focus on reductions in the development lead time or various costs. This study simultaneously applies the proposed method to a laptop PC design and derives an appropriate modular strategy from the same viewpoints as the proposed method. Finally, this paper discusses the availability and additional considerations of the proposed method based on the result of the case study.

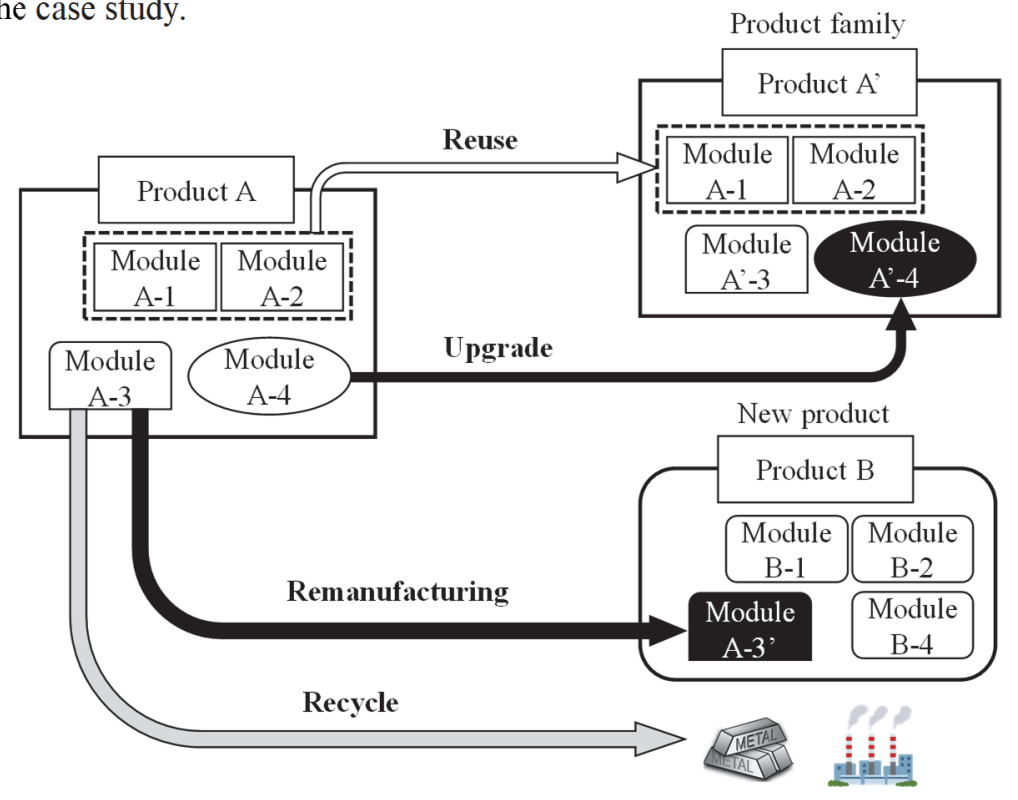

Fig. 1 Ideal material flow of a modular product during its lifecycle.

\section{Modular design method}

\subsection{Previous studies on modular design}

In this section, the paper discusses previous studies that have investigated modular design methods, including a method that was formulated as a multi-objective optimization problem related to the product performance in a family of products using the commonality of modules (Nelson et al., 2001), an optimization method for module combinations focusing on product function and production cost (Fujita and Sakaguchi, 2002), and a study focusing on the functionality of integrations between components via modularization (Oizumi et al., 2016).

As an approach to achieve modularization, a design structure matrix (DSM) method is a renowned, straightforward, and flexible modeling technique that can be used to design, develop, and manage complex systems (Sosa et al., 2003; Eppinger and Browning, 2012). A DSM is created so that the interfaces between modules can be reduced. A DSM analysis can achieve partitioning and relocation using various analytical methods in the case of modularization (Hino, 2009). Using DSM clustering (Sarkar et al., 2013), the row and column elements of the DSM are rearranged, where the elements with strong interactions are grouped, and modularization can be pursued. The sorting 
method is developed by consulting experts, using functions, or using unique algorithms such as the Newman method and the p-median method. In particular, several methods that focus on the usage of functions have been proposed (Tyson and Browning, 2015), whereas methods that simultaneously consider the environment and costs have rarely been attempted.

\subsection{New modular design strategy using Internet of Things}

Figure 2 shows a modular design strategy using the Internet of things (IoT). When the IoT can connect companies to users and suppliers, companies can obtain data from users by monitoring the product usage and then forecast future failures of the product and offer quick suggestions to users of appropriate lifecycle options, such as reuse, remanufacturing, and upgrading. As a result, proposals of appropriate lifecycle options from companies to users are conducive to customer retention for the companies due to after-sale services. In addition, companies can obtain data from suppliers by monitoring the component quality, operation status, and schedule and then selecting the appropriate suppliers to meet the user requirements.

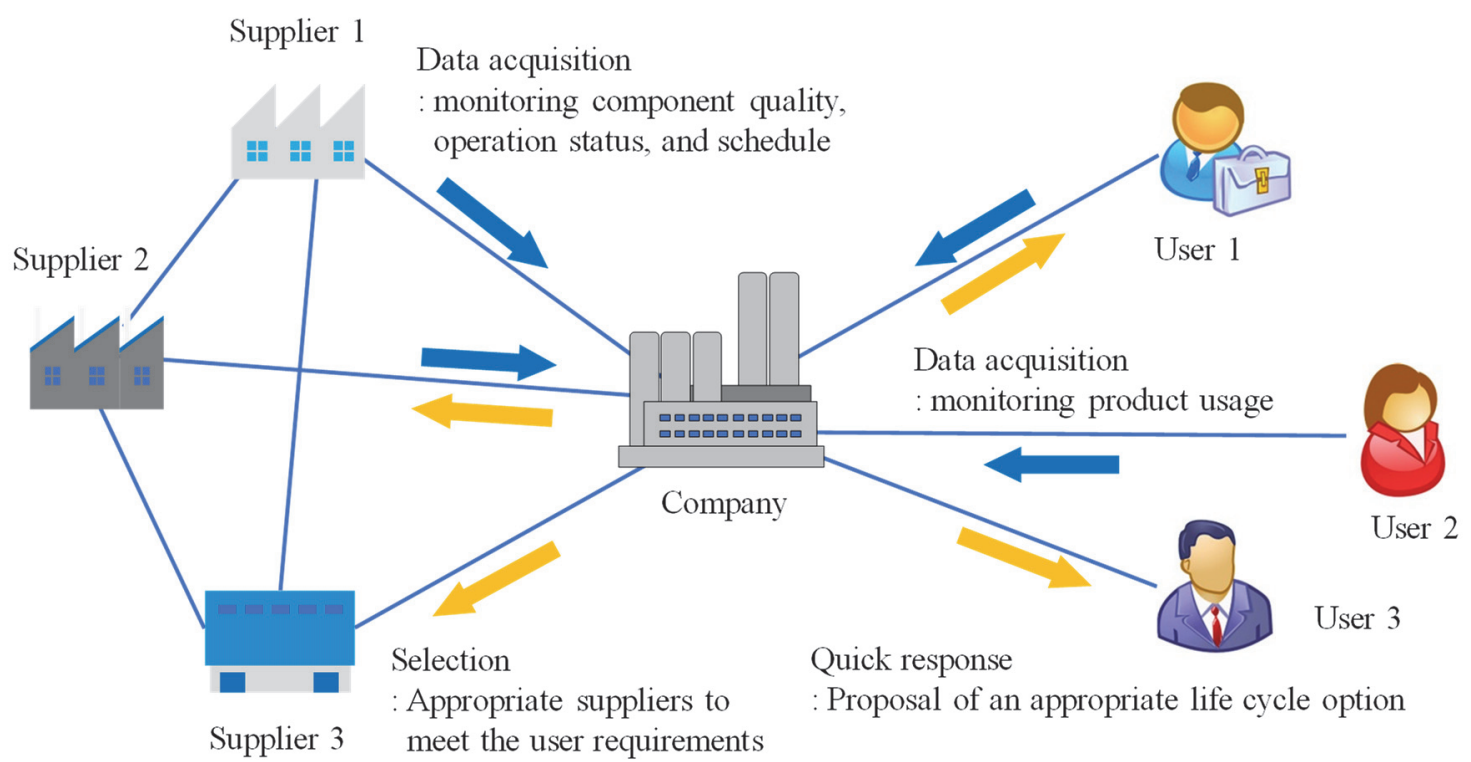

Fig. 2 New modular design strategy using IoT.

\subsection{Supply chain management}

To resolve issues related to global warming, a low-carbon supply chain that can reduce the $\mathrm{CO}_{2}$ emissions is necessary (Yoshizaki et al., 2016; Loo et al., 2018). Regardless of the components being considered, the environmental load, personnel expenses, and transportation costs differ depending on the country of manufacture. In general, when the components are produced in industrialized countries, the cost is higher and the environmental load is lower. Conversely, when the components are produced in countries with emerging economies, the cost is lower and the environmental load is higher (Kokubo et al., 2012; Horiguch et al., 2012). Therefore, a supplier selection method that can achieve both low cost and a low environmental load is optimal. Urata et al. (2017) proposed a design method for global supply chain networks including multiple Asian countries that balances both procurement and transportation costs and material-based $\mathrm{CO}_{2}$ emissions to determine low-carbon suppliers and factory locations, while satisfying the demand requirements.

\subsection{Procedure for modular design}

As described in Section 2.1, there are several modular design methods that focus on functions; however, there are very few methods that simultaneously consider both the environment and economics. Therefore, in this study, the concept of SCM is applied to develop a modular design to consider the economic cost, environmental load, procurement lead time, and component quality simultaneously. The component suppliers are evaluated, and indicators are proposed to comprehensively evaluate the efficiency of the module strategy from the aforementioned viewpoints 
depending on the manner in which the decisions regarding the suppliers and module components are made when multiple suppliers are available for each component. Figure 3 depicts the design flow of the proposed method. For each component, a company selects suppliers from several candidates. For the components to be modularized via integration, the module production site is further set to an arbitrary global location. Finally, the processing site used to assemble all the modules and components is defined as the location where the product is completed. When different architectures, such as modular architecture and integral architecture (Inoue et al., 2011), are represented, the proposed method evaluates each architecture from the viewpoints of the economic cost, environmental load, procurement lead time, and component quality; then, our method further determines the module strategy by identifying the scenario having the highest score.

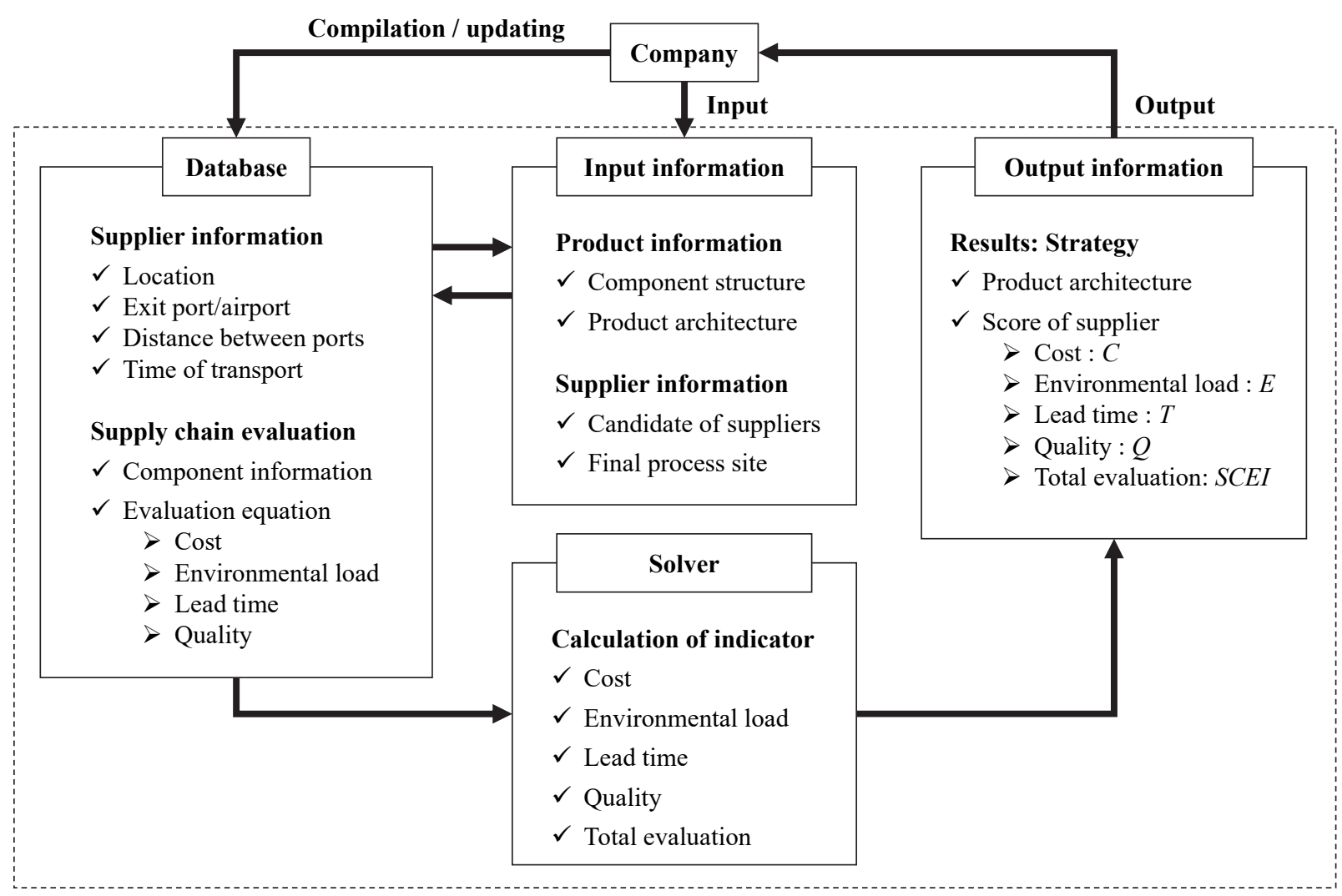

Fig. 3 Design flow to obtain the module strategy and supplier selection.

\subsubsection{Evaluation of the economic cost}

To evaluate the economic cost, the total product cost $C$ is defined as the sum of the costs associated with manufacturing, profit, and transportation of each component $i$ expressed in Eq. (1). In Eq. (1), $C_{\text {manufacturing, } i, C_{\text {profit }, i} \text {, and }}$ $C_{\text {transportation, } i}$ indicate the manufacturing cost, the supplier profit, and the transportation cost of each component $i$, respectively, and $N$ is the number of components. The manufacturing cost of each component is the price of the components, which is determined by considering the material procurement and labor costs. While calculating the profits, the difference in labor costs varies depending on the component manufacturing location and can be expressed as the ratio of the gross domestic product (GDP) per capita of the country of manufacture (GDP manufacturing $)$ to the GDP per capita of the base country $\left(G D P_{b a s e}\right)$.

$$
C=\sum_{i=1}^{N} C_{\text {component }, i}=\sum_{i=1}^{N}\left(C_{\text {manufacturing }, i}+C_{\text {profit }, i}+C_{\text {transportaion }, i}\right)
$$

The supplier profit for each component is defined in Eq. (2) by multiplying the GDP ratio by the profit ratio $\left(P_{\text {ratio }}\right)$ and the manufacturing cost of each component $\left(C_{\text {manufacturing, } i}\right)$ to be modularized. 


$$
C_{\text {profit }, i}=C_{\text {manufacturing }, i} \times \frac{P_{\text {ratio }}}{100-P_{\text {ratio }}} \times \frac{G D P_{\text {manufacture }}}{G D P_{\text {base }}}
$$

The transportation cost of each component is the cost incurred from the time at which the components are shipped to the time at which the components arrive at the destination; these are essentially the fees charged by the shipping company. In general, the transportation price is observed to vary depending on the transportation distance and means of transportation. Transportation costs are calculated using Eqs. (3)-(6). The total transportation cost of each component is indicated by the sum of the transportation costs from the site that manufactures the components to the final processing site by considering the truck transportation cost of each component $\left(C_{\text {truck, }}\right)$, the container shipping cost of each component $\left(C_{\text {shipping, } i}\right)$, and the air transportation cost of each component $\left(C_{a i r, i}\right)$. Here, $m_{i}(\mathrm{~kg})$ is defined as the mass of each component to be transported. $C_{\text {unit }}(\mathrm{Yen} / \mathrm{kg})$ in the trucking cost part of Eq. (4) represents the freight rate of the package, as defined by 69. The transportation cost using a container ship is presented in Eq. (5), whereas the air transportation cost in Eq. (6) can be formulated by confirming the dependency relationship between the transport distance and the mass using the actual tariff.

$$
\begin{aligned}
& C_{\text {transportation }, i}=C_{\text {truck }, i}+C_{\text {shipping }, i}+C_{\text {air }, i} \\
& C_{\text {truck }, i}=C_{\text {unit }} \times m_{i} \\
& C_{\text {shipping }, i}=\left(0.0016 L_{i}+120\right) m_{i}+\left(0.4 L_{i}+1450\right) \\
& C_{\text {air }, i}=\left\{\begin{array}{c|c}
10,269 & m_{i}<20 \\
513 m_{i} & 20 \leq m_{i}<45 \\
399 m_{i} & 45 \leq m_{i}<100 \\
342 m_{i} & m_{i} \geq 100
\end{array}\right\}
\end{aligned}
$$

\subsubsection{Evaluation of the environmental load}

To consider environmental impact of industrial product design and manufacturing, different officially accepted sustainability indicators were investigated. The National Institute for Environmental Studies (NIES) had reviewed the sustainable development indicators, which were developed by national governments and international organizations, and created a database of the type of indicators [NIES, 2020]. Using the database, sustainability indicators such as $\mathrm{CO}_{2}$ emissions, amount of recycled and reused wastes, and use of renewable energy sources that are both directly and indirectly related to the industrial product design and manufacturing were identified and then categorized into three groups considering ecological, economical, and social aspects (Inoue et al., 2012). In this study, $\mathrm{CO}_{2}$ emissions was chosen to evaluate the environmental load for further consideration. The converted $\mathrm{CO}_{2}$ emissions $E_{\text {component, } i}$ of each component $i$ associated with manufacturing and transportation are used as expressed in Eq. (7). In Eq. (7), $E_{\text {manufacturing, } i}$ and $E_{\text {transportation, } i}$ indicate the converted $\mathrm{CO}_{2}$ emissions of manufacturing and transportation, respectively, for each component $i$. As presented in Eq. (8), the converted manufacturing $\mathrm{CO}_{2}$ emissions for each component are calculated

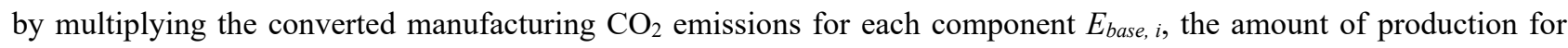
each component $V_{i}$, and the proportion of the thermal power generation ratio in the country of manufacture $P_{\text {manufacture }}$ to the thermal power generation ratio in the base country $P_{\text {base }}$.

As shown in Eq. (9), the converted $\mathrm{CO}_{2}$ emissions for the transportation of each component $E_{\text {transportation, } i}\left(\mathrm{~kg}-\mathrm{CO}_{2} \mathrm{e}\right)$ are calculated by multiplying the converted $\mathrm{CO}_{2}$ emission intensity of each transportation leg $k(k=1 ;$ truck: 0.1635 $\mathrm{kg}-\mathrm{CO}_{2} \mathrm{e} / \mathrm{tkm}, k=2$; container ship: $0.033 \mathrm{~kg}-\mathrm{CO}_{2} \mathrm{e} / \mathrm{tkm}$, and $k=3$; airplane: $\left.1.005 \mathrm{~kg}-\mathrm{CO}_{2} \mathrm{e} / \mathrm{tkm}\right)\left(e_{k}\right)$, the transport distance of each component $L_{i}(\mathrm{~km})$, the mass of each component to be transported $m_{i}(\mathrm{~kg})$, and the amount of production for each component $V_{i}$ (Ministry of Economy, Trade and Industry Japan, 2012).

$$
\begin{aligned}
& E=\sum_{i=1}^{N} E_{\text {component }, i}=\sum_{i=1}^{N}\left(E_{\text {manufacturing }, i}+E_{\text {transportation }, i}\right) \\
& E_{\text {manufacturing }, i}=E_{\text {base }, i} \times V_{i} \times \frac{P_{\text {manufacture }}}{P_{\text {base }}} \\
& E_{\text {transportation }, i}=\sum_{k=1}^{3} e_{k} \times L_{i} \times m_{i} \times V_{i}
\end{aligned}
$$




\subsubsection{Evaluation of the procurement lead time}

The procurement lead time $T$ indicates the number of days between the time when an order is placed for a certain item by a buyer to the time of delivery of the item. To simplify this comparison, the lead time for each form of transportation (truck, container shipping, and air transportation) is defined and the maximum value of the number of days for each type of transportation is calculated as represented in Eq. (10). With respect to truck and air transportation, this study assumes that the lead time is one day when used once. The lead time of each component $i$ due to the transportation of the shipping container ( $\left.T_{\text {shipping, } i}\right)$ (day) is assumed to be dependent on the transportation distance, as defined in Eq. (11). To obtain the solution of Eq. (11), the value obtained by rounding down to the decimal point is defined as the lead time.

$$
\begin{aligned}
& T=\max _{0 \leq i \leq N}\left\{T_{\text {truck }, i}, T_{\text {shipping }, i}, T_{\text {air }, i}\right\} \\
& T_{\text {shipping }, i}=0.0015 \times L_{i}
\end{aligned}
$$

\subsubsection{Evaluation of the component quality}

A five-point scale is used to evaluate the differences in quality and manufacturing technology depending on the manufacturing site of the supplier, with one being the lowest quality and five being the highest quality. It is assumed that the quality can be judged using the data handled by a company, such as the failure and/or yield rate, and that the total product quality $Q$ is defined as the average of the quality scores of each component $\left(Q_{\text {component, } i}\right)$ as presented in Eq. (12).

$$
Q=\frac{1}{N} \sum_{i=1}^{N} Q_{\text {component }, i}
$$

\subsubsection{Supply chain evaluation index}

The supply chain evaluation indicator (SCEI) defined in Eq. (13) is calculated using the evaluation variables that were derived in Sections 2.4.1-2.4.4. As the value of SCEI increases, the modular strategy is considered to become increasingly appropriate. More specifically, such a case with high SCEI indicates high quality, low cost, low environmental load, and short delivery time and this determines the best modular strategy. Using the $S C E I$ value, a designer can search for a combination of clusters that can ensure appropriate modularization when considering multiple suppliers.

$$
S C E I=\frac{Q}{C \times E \times T}
$$

\section{Case study: Supply chain strategy for laptop components 3.1 Setting the design problem}

This study demonstrates an application of the proposed method to compiling and assembling laptop components. In particular, this case study focuses on the modularization of three laptop components: the CPU, motherboard, and memory. By applying the proposed method to these three components, appropriate module suppliers are defined in terms of SCM. A laptop was selected to perform this study because each component is standardized and because individual modules are separately purchased from multiple manufacturers, which makes it easy to obtain information about the pricing as well as the manufacturing location under realistic conditions. In actual laptop manufacturing, more than three components are used. However, these components are assembled as independent modules from the viewpoint of maintainability or are integrated to form a module from the viewpoint of appearance and miniaturization. Therefore, because modularized products are mixed, a sustainable modular strategy can be validated using a three-component evaluation scenario.

This case study assumes that the target laptop is a mobile laptop with a 13.3-inch LCD screen and a weight of 1.6 $\mathrm{kg}$. It is further assumed that production volume of each component is $100\left(V_{i}=100\right)$. Table 1 presents the component information of the case study laptop. The cost of each component was determined by considering the actual selling prices, and the masses of each component were estimated by disassembling and weighing the components of an actual laptop, even though the change in weight due to the integration of the components was not considered. For each component, Table 2 shows the locations of the candidate suppliers and the final processing site at which all the 
components are assembled. The capital letters represent the region, e.g., $\mathrm{A}=$ Asia and $\mathrm{W}=$ the west including Europe and the United States, whereas the lower case letters represent the quality level of the supplier, $Q$, e.g., $\mathrm{a}=5, \mathrm{~b}=4, \mathrm{c}=$ 3 , and $d=2$. Major companies that actually manufacture each component were researched and selected by identifying the country in which their respective production factories are located. The final processing site was further chosen using Table 2: Asia and the west were used to assemble all the components.

Table 1 Information concerning each component.

\begin{tabular}{c|c|c}
\hline Component & Mass $(\mathrm{g})$ & Cost (Yen) \\
\hline CPU & 7 & 18,000 \\
\hline Motherboard & 100 & 10,000 \\
\hline Memory & 15 & 8,000 \\
\hline
\end{tabular}

Table 2 The location and quality of the suppliers of each laptop component.

\begin{tabular}{c|c|c|c|c}
\hline \hline \multirow{2}{*}{ Components } & \multicolumn{4}{|c}{ Supplier candidate (its quality) } \\
\hline CPU & A-a1 $(Q: 5)$ & A-d1 $(Q: 2)$ & W-a4 $(Q: 5)$ & - \\
MB & A-a2 $(Q: 5)$ & A-c1 $(Q: 3)$ & W-b2 $(Q: 4)$ & W-d2 $(Q: 2)$ \\
Memory & A-a3 $(Q: 5)$ & A-b1 $(Q: 4)$ & W-a5 $(Q: 5)$ & - \\
\hline Final processing site & A & W & & \\
\hline
\end{tabular}

\subsection{Results and Discussion}

For each of the two final processing sites, Asia (A) and the west including Europe and the United States (W), each evaluation value was obtained using the proposed method. Tables 3 and 4 show the results for the suppliers used in these final processing sites. In Tables 3 and 4, the supplier column provides the supplier and transportation means. Transport by container shipping includes truck transportation from the supplier's factory to the nearest port and container vessel transport from that port to the port nearest to the final processing site. Transport by airplane includes truck transportation from the supplier's factory to the nearest airport and transportation from that airport to the airport nearest to the final processing site.

The supplier selections with the highest and lowest SCEI value are presented in Tables 3 and 4. The highest score of the best case is well balanced in all perspectives including the economic cost, environment load, lead time, and component quality. For example, Tables 3 in the case of Asia (A) as the final processing site shows that the best case has a high score for the lead time and quality because the nearest and highest quality suppliers are selected, as shown in Fig. 4, whereas the evaluations of the cost and environmental load are low due air transportation. Conversely, container-shipping transportation has a long lead time but has the highest score with respect to the cost and environmental load. Therefore, the second highest score includes container-shipping transportation.

Table 4, in the case of Europe and the United States (W) as the final processing site, shows that the best case is well balanced with respect to the cost and environmental load. A CPU supplier in Asia was selected even though the final processing site is in Europe, as shown in Fig. 4, because the selected supplier has a high quality and a low thermal power generation ratio in the country of manufacture. 
Inoue, Shuho Yamada, Miyajima, Ishii, Hasebe, Aoyama, Tetsuo Yamada and Bracke, Journal of Advanced Mechanical Design, Systems, and Manufacturing, Vol.14, No.2 (2020)

Table 3 Evaluation results for the suppliers (final processing site: Asia (A)).

\begin{tabular}{|c|c|c|c|c|c|c|c|c|}
\hline & \multicolumn{3}{|c|}{ "Suppliers (transportation means) } & \multirow{2}{*}{$\begin{array}{c}C \\
\text { (mil. Yen) }\end{array}$} & \multirow{2}{*}{$\begin{array}{c}E \\
\left(\mathrm{~kg}-\mathrm{CO}_{2 \mathrm{e}}\right)\end{array}$} & \multirow{2}{*}{$\begin{array}{c}T \\
\text { (hours) }\end{array}$} & \multirow[b]{2}{*}{$Q$} & \multirow{2}{*}{$\begin{array}{c}S C E I \\
\left(\times 10^{14}\right)\end{array}$} \\
\hline & CPU & Motherboard & Memory & & & & & \\
\hline \multicolumn{9}{|c|}{ High evaluation (top 3) values, final processing site: Asia (A) } \\
\hline 1 & $\begin{array}{l}\text { A-al } \\
\text { (air) }\end{array}$ & $\begin{array}{l}\text { A-a2 } \\
\text { (air) }\end{array}$ & $\begin{array}{l}\text { A-a3 } \\
\text { (air) }\end{array}$ & 3.632 & 1927.5 & 25 & 5.00 & 2857.11 \\
\hline 2 & $\begin{array}{c}\text { A-a1 } \\
\text { (shipping) }\end{array}$ & $\begin{array}{l}\text { W-b2 } \\
\text { (air) }\end{array}$ & $\begin{array}{c}\text { A-a3 } \\
\text { (shipping) }\end{array}$ & 3.614 & 1458.5 & 34 & 4.67 & 2603.68 \\
\hline 3 & $\begin{array}{l}\text { A-a1 } \\
\text { (air) }\end{array}$ & $\begin{array}{l}\text { A-a2 } \\
\text { (air) }\end{array}$ & $\begin{array}{l}\text { A-b1 } \\
\text { (air) }\end{array}$ & 3.632 & 1899.7 & 26 & 4.67 & 2601.62 \\
\hline \multicolumn{9}{|c|}{ Lowest evaluation, final processing site: Asia (A) } \\
\hline 1 & $\begin{array}{l}\text { A-d1 } \\
\text { (air) }\end{array}$ & $\begin{array}{c}\text { W-d2 } \\
\text { (shipping) }\end{array}$ & $\begin{array}{l}\text { A-b1 } \\
\text { (air) }\end{array}$ & 3.628 & 1896.8 & 329 & 2.67 & 117.780 \\
\hline
\end{tabular}

Table 4 Evaluation result for the suppliers (final processing site: west including Europe and the United States (W)).

\begin{tabular}{|c|c|c|c|c|c|c|c|c|}
\hline & \multicolumn{3}{|c|}{ "Suppliers (transportation means) } & \multirow{2}{*}{$\begin{array}{c}C \\
\text { (mil. Yen) }\end{array}$} & \multirow{2}{*}{$\begin{array}{c}E \\
\left(\mathrm{~kg}-\mathrm{CO}_{2 \mathrm{e}}\right) \\
\end{array}$} & \multirow{2}{*}{$\begin{array}{c}T \\
\text { (hours) }\end{array}$} & \multirow[b]{2}{*}{$Q$} & \multirow{2}{*}{$\begin{array}{c}S C E I \\
\left(\times 10^{14}\right)\end{array}$} \\
\hline & CPU & Motherboard & Memory & & & & & \\
\hline \multicolumn{9}{|c|}{ High evaluation (top 3) values, final processing site: west including Europe and the United States (W) } \\
\hline 1 & $\begin{array}{l}\text { A-a1 } \\
\text { (air) }\end{array}$ & $\begin{array}{l}\text { W-b2 } \\
\text { (air) }\end{array}$ & $\begin{array}{l}\text { W-a5 } \\
\text { (air) }\end{array}$ & 3.965 & 1365.8 & 35 & 4.67 & 2462.21 \\
\hline 2 & $\begin{array}{l}\text { A-a1 } \\
\text { (air) }\end{array}$ & $\begin{array}{l}\text { W-b2 } \\
\text { (air) }\end{array}$ & $\begin{array}{l}\text { A-a3 } \\
\text { (air) }\end{array}$ & 3.880 & 1397.4 & 35 & 4.67 & 2459.26 \\
\hline 3 & $\begin{array}{l}\mathrm{W}-\mathrm{a} 4 \\
\text { (air) }\end{array}$ & $\begin{array}{l}\text { W-b2 } \\
\text { (air) }\end{array}$ & $\begin{array}{l}\text { W-a5 } \\
\text { (air) }\end{array}$ & 4.156 & 1353.0 & 34 & 4.67 & 2440.76 \\
\hline \multicolumn{9}{|c|}{ Lowest evaluation, final processing site: west including Europe and the United States (W) } \\
\hline 1 & $\begin{array}{c}\text { A-d1 } \\
\text { (shipping) }\end{array}$ & $\begin{array}{c}\mathrm{W}-\mathrm{d} 2 \\
\text { (shipping) }\end{array}$ & $\begin{array}{c}\text { A-b1 } \\
\text { (shipping) }\end{array}$ & 3.779 & 1990.3 & 491 & 2.67 & 72.2169 \\
\hline
\end{tabular}
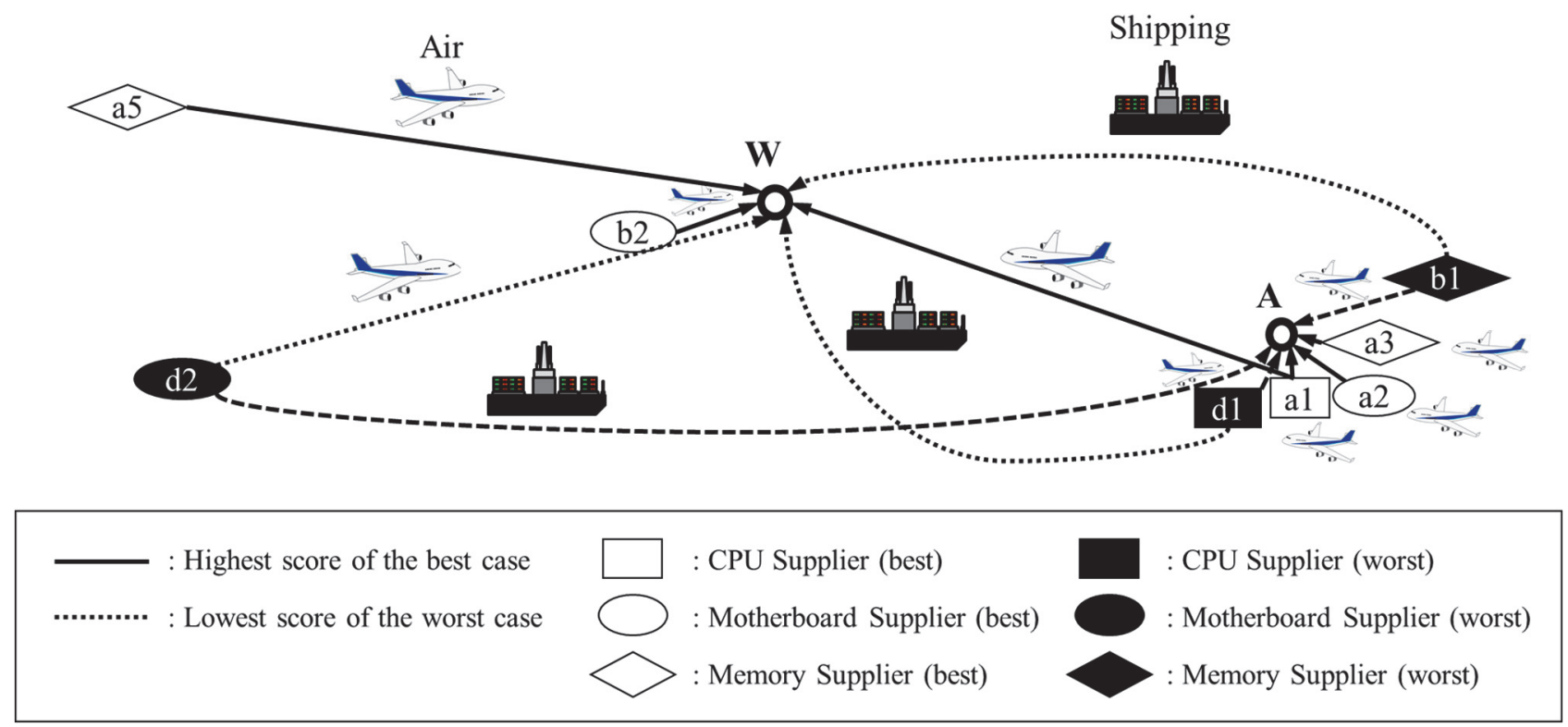

Fig. 4 Best and worst case evaluation results for the suppliers (final processing sites: Asia (A) and the west (W)). 
Inoue, Shuho Yamada, Miyajima, Ishii, Hasebe, Aoyama, Tetsuo Yamada and Bracke, Journal of Advanced Mechanical Design, Systems, and Manufacturing, Vol.14, No.2 (2020)

\section{Conclusions}

This study proposed a modular design strategy and its evaluation method based on the concept of SCM to promote the formation of sustainable societies. The proposed method includes an evaluation index that evaluates the modular architecture and supply chain based on four perspectives, that is, the economic cost, environmental load in manufacturing and transportation, procurement lead time, and component quality. The proposed index, referred to as SCEI, evaluates the design of the modular strategy according to the four aforementioned perspectives. Finally, this study applied the proposed method and index to the design problem of the module composition of a laptop and derived the necessary supplier information with respect to each destination, i.e., Asia and the west including Europe and the United States.

\section{Acknowledgments}

This research was partially supported by the Japan Society for the Promotion of Science (JSPS), KAKENHI, Grant-in-Aid for Scientific Research (C), 17K01273 and Grant-in-Aid for Scientific Research (A), 18 H03824.

\section{References}

Browning, T. R., Design structure matrix extensions and innovations: a survey and new opportunities, IEEE Transactions on Engineering Management, Vol. 63, No. 1 (2016), pp. 27-52.

Eppinger, S. D. and Browning, T. R., Design Structure Matrix Methods and Applications (2012), MIT Press.

European Commission, Closing the loop: Commission delivers on Circular Economy Action Plan (online), available from < http://europa.eu/rapid/press-release_IP-19-1480_en.htm>, (accessed on 1 January, 2020).

Fujita, K. and Sakaguchi, H., Optimization methodologies for product variety design (2nd report, optimization method for module commonalization), Transactions of the Japan Society of Mechanical Engineers, Series C, Vol.68, No.666 (2002), pp.683-691 (in Japanese).

Hino, S., Practical Modular Design (2009), Nikkei BP (in Japanese).

Horiguchi, K., Tsujimoto, H., Yamaguchi, H. and Itsubo, N., Development of greenhouse gases emission intensity in Eastern Asia using Asian International input-output table, Proceedings of the 7th Meeting of the Institute of Life Cycle Assessment (2012), pp.236-239.

Inoue, M., Mogi, R., Nahm, Y-E. and Ishikawa, H., Design Support for "Suriawase": Japanese Way for Negotiation among Several Teams, Improving Complex Systems Today (2011), pp. 385-392, Springer-Verlag.

Inoue, M., Lindow, K., Stark, R., Tanaka, K., Nahm, Y-E. and Ishikawa, H., Decision-making support for sustainable product creation, Advanced Engineering Informatics, Vol. 26, Issue 4 (2012), pp. 782-792.

Kokubu, K., Itsubo, N., Nakashima, M. and Yamada, T., Constructing low-carbon supply chain in Asia and the role of accounting, Kaikei (Accounting), Vol.182, No.1 (2012), pp.82-97 (in Japanese).

Loo, H. S., Chew, B. C. and Hamid, S. R., Exploring the factors and strategies in implementation of sustainable land transport system in Ayer Keroh, Melaka", Journal of Advanced Manufacturing Technology, Vol. 12, No. 1 (2018), pp. 159-174.

Ministry of Economy, Trade and Industry Japan, Carbon footprint of products system trial project $\mathrm{CO}_{2}$ reduced quantity common basic unit database ver. 4.01 (domestic data) (2012) (in Japanese).

National Institute for Environmental Studies (NIES), Sustainable Development Indicators Database (online), available from < http://www.nies.go.jp/sdi-db/search_e.php >, (accessed on 1 January, 2020).

Nelson, S. A., Parkinson, M. B. and Papalambros, P. Y., Multicriteria optimization in product platform design, Journal of Mechanical Design, Vol. 123, No. 2 (2001), pp. 119-204.

Oizumi, K., Aruga, K. and Aoyama, K., Module commonization in product family incorporating fine-tune improvement, Transactions of the JSME (in Japanese), Vol. 82, No. 843 (2016), DOI: 10.1299/transjsme.16-00071.

Sarkar, S., Dong, A., Henderson, J.A. and Robinson, P.A., Spectral characterization of hierarchical modularity in product architectures, Journal of Mechanical Design, Vol. 136, No. 1 (2013), DOI: 10.1115/1.4025490. 
Inoue, Shuho Yamada, Miyajima, Ishii, Hasebe, Aoyama, Tetsuo Yamada and Bracke, Journal of Advanced Mechanical Design, Systems, and Manufacturing, Vol.14, No.2 (2020)

Sosa, M. E., Eppinger, S. D. and Rowles, C. M., Identifying modular and integrative systems and their impact on design team interactions, Journal of Mechanical Design, Vol. 125 (2003), pp. 240-252.

Sustainability Design Institute, Global Multi Value Circulation (in Japanese, online), available from < http://susdi.org/wp/mvc/entrance/>, (accessed on 1 January, 2020).

Urata, T., Yamada, T., Itsubo, N. and Inoue, M., Global supply chain network design and Asian analysis with material-based carbon emissions and tax, Computers \& Industrial Engineering, Vol. 113 (2017), pp. 779-792.

Yoshizaki, Y., Yamada, T., Itsubo, N. and Inoue, M., Material based low-carbon and economic supplier selection with estimation of GHG emissions and affordable cost increment for parts production among multiple Asian countries, Journal of Japan Industrial Management Association, Vol. 66 (2016), pp. 435-442. 